\title{
STRATEGI PENGELOLAAN SUMBERDAYA PERIKANAN PELAGIS SECARA TERPADU DAN BERKELANJUTAN DI PERAIRAN TELUK TOMINI
}

\author{
Syahrul \\ Fakultas Perikanan dan Ilmu Kelautan \\ Universitas Muslim Indonesia, Makassar \\ E-mail: syahruld@yahoo.com
}

Diterima 13 April 2012 - Disetujui 20 Juni 2012

\begin{abstract}
ABSTRAK
Penelitian ini bertujuan untuk melihat potensi, tingkat pemanfaatan, status keberlanjutan sumberdaya perikanan pelagis di Teluk Tomini. Penelitian dilakukan dengan menggunakan metode survei. Pengambilan sampel dilakukan secara cluster random sampling sebanyak 86 orang. Metode analisis data dilakukan secara deskriptif dan kuantitatif. Analisis data yang digunakan yaitu produksi surplus dari Schaefer dan Fox dan analisis keberlanjutan sumber daya perikanan pelagis. Hasil analisis menunjukkan bahwa potensi lestari sumber daya perikanan pelagis di Teluk Tomini sebesar 93.071,21 ton/tahun (model Schaefer) dan 104.044,04 ton/tahun (model Fox) dengan tingkat pemanfaatan tahun 2002-2011 masih di bawah potensi lestari. Dimensi etika, hukum dan regulasi kurang mendukung keberlanjutan sumber daya perikanan pelagis. Peraturan belum memadai dalam pengelolaan terpadu perairan Teluk Tomini. Pengelolaan sumberdaya perikanan pelagis di perairan Teluk Tomini memerlukan pembentukan kawasan terpadu.
\end{abstract}

Kata Kunci: Teluk Tomini, pelagis, potensi, keberlanjutan, terpadu

\section{Abstract: Strategy of Integrated and Sustainable Pelagic Fishery Resource Management at Tomini Bay. By: Syahrul.}

The purpose of the study is to observe potention, degree of utilization, status of pelagic fishery resource sustainability at Tomini Bay. The research employs survey method. Sampling is done by random cluster sampling amounted 86 people. Data analysis method uses descriptive and quantitatif method. Data analysis apllies surplus production from Schaefer and Fox, pelagic fishery resource sustainability analysis. Analysis of the study shows that sustainable potention of pelagic fishery resource at Tomini Bay amount 93.071,21 tons/year (Schaefer model), and 104.044,04 tons/year (Fox model) with degree of utilization in 2022-2011 is under sustainable potention. Ethical dimension, law and regulation are less supporting the sustainabiliy of pelagic fihsery resource. Regulation in integrated management of Tomini Bay waters is inadequately. It is necessary to establish integrated area of pelagic fishery resource management at Tomini Bay.

Keywords: Tomini Bay, pelagic, potention, sustainable, integrated 


\section{PENDAHULUAN}

Perairan Teluk Tomini memiliki sumberdaya ikan yang cukup besar untuk mendukung perekonomian daerah dan devisa negara. Beberapa jenis ikan ekonomis penting yang terdapat di wilayah ini antara lain; ikan malalugis (Decapterus macarellus), yellow fin tuna (Thunnus albacares), cakalang (Katsuwonus pelamis); dan beberapa jenis ikan karang. Berdasarkan hasil penelitian Balai Riset Perikanan Laut (2005) diketahui bahwa perairan Teluk Tomini, Laut Maluku dan Laut Seram memiliki potensi sumberdaya ikan pelagis sekitar 486 ribu ton per tahun dimana $80 \%$ diantaranya berupa ikan pelagis kecil. Selanjutnya dikatakan bahwa tingkat eksploitasi pelagis kecil telah mencapai lebih dari $50 \%$ dan pelagis besar baru mencapai 21\%. Eksploitasi diduga belum memberikan dampak yang nyata pada laju penangkapan dan biologi sumberdaya.

Tingkat pemanfaatan ikan pelagis di perairan Teluk Tomini yang masih rendah memungkinkan untuk dikembangkan. Selama ini usaha perikanan pelagis di peraran Teluk Tomini umumnya masih berskala kecil (small scale fishery), yaitu dengan menggunakan armada penangkapan relatif kecil dan hari layar yang pendek antara 1-3 hari namun penangkapan cukup intensif dalam arti bahwa penangkapan akan selalu dijalankan sejauh kondisi untuk aktivitas itu memungkinkan. Jumlah nelayan yang aktif dan tercatat di Sulawesi Utara, Gorontalo dan Sulawesi Tengah sebanyak 51.684 RTP (BRPL, 2005).

Hasil penelitian Olii (2007) menunjukkan bahwa potensi perikanan wilayah Teluk Tomini sebesar 590.620 ton per tahun namun tingkat pemanfaatannya sebesar 197.640 ton per tahun $(33,46 \%)$. Adapun potensi perikanan pelagis besar sebesar 39.420 ton per tahun dan tingkat pemanfaatanya sebesar $37,01 \%$. Selanjutnya Masyahoro (2004) dari hasil penelitiannya di perairan Kabupaten Parigi Moutong (Teluk Tomini) menunjukkan bahwa upaya optimum unit penangkapan purse seine untuk ikan tongkol sebesar 10.813 trip per tahun, ikan layang sebesar 7.840 trip per tahun dan ikan kembung sebesar 8.129 trip per tahun sementara upaya penangkapan purse seine saat ini sebesar 5.005,29 trip sehingga masih dimungkinkan peningkatan trip penangkapan. Hasil-hasil penelitian tersebut menunjukkan bahwa tingkat eksploitasi sumberdaya perikanan pelagis di perairan Teluk Tomini diperkirakan belum optimal atau masih under fishing sehingga masih dapat dikembangkan.

Secara geografis Teluk Tomini terletak pada 3 (tiga) daerah administrasi provinsi yaitu Provinsi Sulawesi Utara, Gorontalo dan Sulawesi Tengah. Jumlah kabupaten/kota yang berbatasan langsung dengan perairan Teluk Tomini sebanyak 9 (sembilan) kabupaten/ kota yang berada di Provinsi Gorontalo dan Sulawesi Tengah. Kabupaten/kota lainnya yang terletak di Provinsi Sulawesi Utara secara langsung berbatasan dengan Laut Seram dan Laut Maluku.

Dalam Undang-Undang Republik Indonesia Nomor 32 Tahun 2004 tetang Pemerintahan Daerah Pasal 18 dijelaskan bahwa kewenangan untuk mengelola sumberdaya di wilayah laut paling jauh 12 (dua belas) mil laut diukur dari garis pantai ke arah laut lepas dan/atau ke arah perairan kepulauan untuk provinsi dan $1 / 3$ (sepertiga) dari wilayah kewenangan provinsi untuk kabupaten/kota. Ini berarti bahwa setiap provinsi dan kabupaten dapat menyusun rencana pengelolaan sumberdaya perikanan secara sendiri-sendiri sesuai dengan kewenangan yang diberikan oleh undang-undang. Hal ini akan berdampak kurang baik bagi keberlanjutan sumberdaya perikanan karena setiap daerah berusaha untuk memanfaatkan sumberdaya tersebut sebesar-besarnya. Selain itu karena sumberdaya ikan pelagis bersifat dinamis dan dapat berpindah-pindah dari daerah perairan kabupaten/provinsi yang satu ke perairan kabupaten/provinsi lainnya sehingga memungkinkan nelayan yang berada di suatu kabupaten/provinsi akan menangkap ikan di perairan kabupaten/provinsi lainnya. 
Sumberdaya perikanan pelagis di perairan Teluk Tomini di duga masih under fishing, untuk itu diperlukan konsep pengembangan perikanan untuk mencapai laju eksploitasi optimum. Besarnya laju eksploitasi optimum sangat bergantung kepada pembuat kebijakan (Koswara, 2009). Selama in kebijakan pengelolaan sumberdaya perikanan pelagis di perairan Teluk Tomini dilakukan secara parsial berdasarkan pendekatan kewilayahan secara geografis dan belum dilakukan secara terpadu berdasarkan pendekatan kawasan ekologis. Untuk itu selayaknya sumberdaya perikanan pelagis di perairan Teluk Tomini dikelola secara terpadu untuk menjamin keberlanjutannya. Penelitian ini bertujuan mengestimasi potensi dan tingkat pemanfaatan serta status keberlanjutan sumberdaya perikanan pelagis di perairan Teluk Tomini. Kemudian, juga mengkaji aspek hukum dalam pemanfaatan sumberdaya perikanan pelagis di perairan Teluk Tomini. Berdasarkan hasil tersebut disusun konsep keterpaduan dalam pengelolaan dan pengembangan sumberdaya perikanan pelagis di perairan Teluk Tomini.

\section{METODOLOGI}

\section{Lokasi dan Waktu Penelitian}

Penelitian ini dilaksanakan di kawasan perairan Teluk Tomini pada tahun 2011.

\section{Metode dan Responden}

Metode yang dipergunakan dalam penelitian ini adalah metode survei. Metode survei adalah pengamatan atau penyelidikan yang kritis untuk mendapatkan keterangan yang baik terhadap suatu persoalan tertentu pada lokasi tertentu (Nazir, 2003).

Pengambilan sampel dilakukan secara cluster random sampling yakni dengan menggolong-golongkan dalam kelompok yang sejenis (Sudrajat, 2006). Jumlah sampel sebanyak 86 orang informan terdiri dari 75 orang nelayan dan 11 orang pegawai Dinas Perikanan dan Kelautan.

\section{Sumber Data}

Data primer diperoleh dari hasil wawancara/inteview dan curah pendapat dari informan. Data sekunder diperoleh melalui studi pustaka dengan cara menelaah laporanlaporan data statistik perikanan tangkap, hasilhasil penelitian sebelumnya dan publikasi melalui media cetak yang berhubungan dengan penelitian.

\section{Teknik Analisis Data}

\section{Analisis Tingkat Pemanfaatan Sumberdaya Perikanan Pelagis}

Analisis tingkat pemanfaatan sumberdaya perikanan pelagis di perairan Teluk Tomini dilakukan dengan metode produksi surplus dari Schaefer dan Fox untuk menentukan hasil tangkapan maksimum lestari (Maximum Sustainable Yield/ MSY) dan upaya optimal baik untuk masing-masing kabupaten/kota maupun secara kumulatif pada perairan Teluk Tomini. Adapun tahapan-tahapan analisis tingkat pemanfaatan sumberdaya perikanan pelagis di perairan Teluk Tomini adalah sebagai berikut :

1. Menyusun data produksi dalam satuan bobot (ton) dan upaya penangkapan (effort) dalam satuan trip secara time series berdasarkan jenis alat tangkap

$$
\text { CPUE }=\frac{\text { Hasil Tangkapan }}{\text { Upaya Penangkapan }} \ldots \ldots . . . .(1)
$$

2. Menghitung catch per unit effort (CPUE)

3. Melakukan standarisasi effort.

Standarisasi effort dilakukan karena di wilayah penelitian banyak alat tangkapyang digunakan (multi gear) untuk menangkap beberapa jenis ikan (multi species) sehingga diperlukan satuan pengukuran yang setara. Teknik standarisasi effort mengikuti formulasi yang dikemukakan oleh King (1995) yakni : 


$$
\begin{aligned}
& \mathrm{E}_{\mathrm{it}}=\Phi_{\mathrm{it}} \mathrm{D}_{\mathrm{it}} \\
& \text { Dengan } \quad \\
& \Phi_{\mathrm{it}}=\frac{\mathrm{U}_{\mathrm{it}}}{\mathrm{U}_{\mathrm{std}}}
\end{aligned}
$$

Dimana :

$\mathrm{E}_{\mathrm{it}}=$ Effort dari alat tangkap yang distandarisasi/ Effort of standard fishing gear;

$\mathrm{D}_{\mathrm{it}}=$ Jumlah hari laut (fishing days) dari alat tangkap $i$ pada waktu $t$ /Total fishing days of fishing gear i at time $t$;

$\Phi_{\text {it }}=$ Nilai kekuatan menangkap (fishing power) dari alat tangkap $i$ pada waktu $t$ / Fishing power of fishing gear $i$ at time $t$;

$\mathrm{U}_{i \mathrm{t}}=$ catch per unit effort (CPUE) dari alat tangkap $i$ pada waktu $t /$ Catch per unit effort (CPUE) of fishing gear i at time;

$\mathrm{U}_{\text {std }}=$ catch per unit effort (CPUE) dari alat tangkap yang dijadikan dasar standarisasi/Catch per unit effort (CPUE) of standardize fishing gear

Melakukan estimasi Maximum Sustainable Yield (MSY)

Estimasi MSY dilakukan dengan menggunakan model produksi surplus dari Schaefer dan Fox. Formulasi kedua model tersebut adalah sebagai berikut :

Formulasi Schaefer :

$\mathrm{CPUE}_{\mathrm{t}}=\mathrm{U}_{\mathrm{t}}=\mathrm{a}-\mathrm{bE}_{\mathrm{t}}$

$\mathrm{C}_{\mathrm{t}}=\mathrm{aE}_{\mathrm{t}}-\mathrm{bE}_{\mathrm{t}}^{2}$

Dengan menggunakan analisis regresi sederhana dari persamaan (2.4) dapat dihitung nilai a dan b sehingga dapat diestimasi hasil tangkapan maksimum dan upaya optimal sebagai berikut :
$\left.\begin{array}{l}\mathrm{C}_{\mathrm{MSY}}=\mathrm{a}^{2} / 4 \mathrm{~b} \\ \mathrm{E}_{\mathrm{MSY}}=\mathrm{a} / 2 \mathrm{~b}\end{array}\right\}$

Formulasi Fox :

In CPUE $=\ln U_{t}=a-b E_{t}$

$C_{t}=E_{t} e^{(a-b E)}$

Dengan menggunakan analisis regresi sederhana dari persamaan (2.7) dapat dihitung nilai a dan $b$ sehingga dapat diestimasi hasil tangkapan maksimum dan upaya optimal sebagai berikut :

$$
\left.\begin{array}{l}
\mathrm{C}_{\mathrm{MSY}}=1 / \mathrm{b} \mathrm{e}\left({ }^{\mathrm{a}-1}\right) \\
\mathrm{E}_{\mathrm{opt}}=1 / \mathrm{b}
\end{array}\right\}
$$

Analisis Keberlanjutan Sumberdaya Perikanan Pelagis

Analisis keberlanjutan pada penelitian ini menggunakan metode Raps-Tomini (Rapid appraisal for pelagic resource of Tomini) yang merupakan modifikasi dari metode Rapfish (Rapid Appraisal for Fisheries) adalah suatu metode untuk mengevaluasi status keberlanjutan dari pengelolaan perikanan secara multidisipliner yang dikembangkan oleh Pusat Perikanan Universitas British Columbia, Vancouver, Canada (Alder et al, 2000). Raps-Tomini didasarkan pada teknik ordinasi dengan menggunakan Multi-DimensionalScaling (MDS). MDS adalah teknik statistik yang mencoba melakukan transformasi multi dimensi ke dalam dimensi yang lebih rendah. Prosedur analisis Raps-Tomini dapat dilihat pada Gambar 1.

Analisis Raps-Tomini dimulai dengan mereview atribut dan mendefinisikan perikanan yang akan dianalisis, dalam hal ini didasari atas alat tangkap yang digunakan untuk menangkap ikan pelagis yakni : pukat kantong (seine net), pukat cincin (purse sein), jaring insang 
(gill net), jaring angkat (lift net) dan pancing (hook and line). Kemudian dilakukan scoring berdasarkan hasil review dari atribut yang telah ditentukan. Kemudian dilakukan MDS untuk menentukan posisi relatif perikanan terhadap ordinasi Baik dan Buruk. Selanjutnya dilakukan analisis Monte Carlo dan Leverage untuk menentukan aspek ketidakpastian dan anomali dari atribut yang dianalisis. Pada analisis MDS, objek atau titik yang diamati dipetakan ke dalam ruang dua atau tiga dimensi, sehingga objek atau titik tersebut diupayakan sedekat mungkin terhadap titik asal.

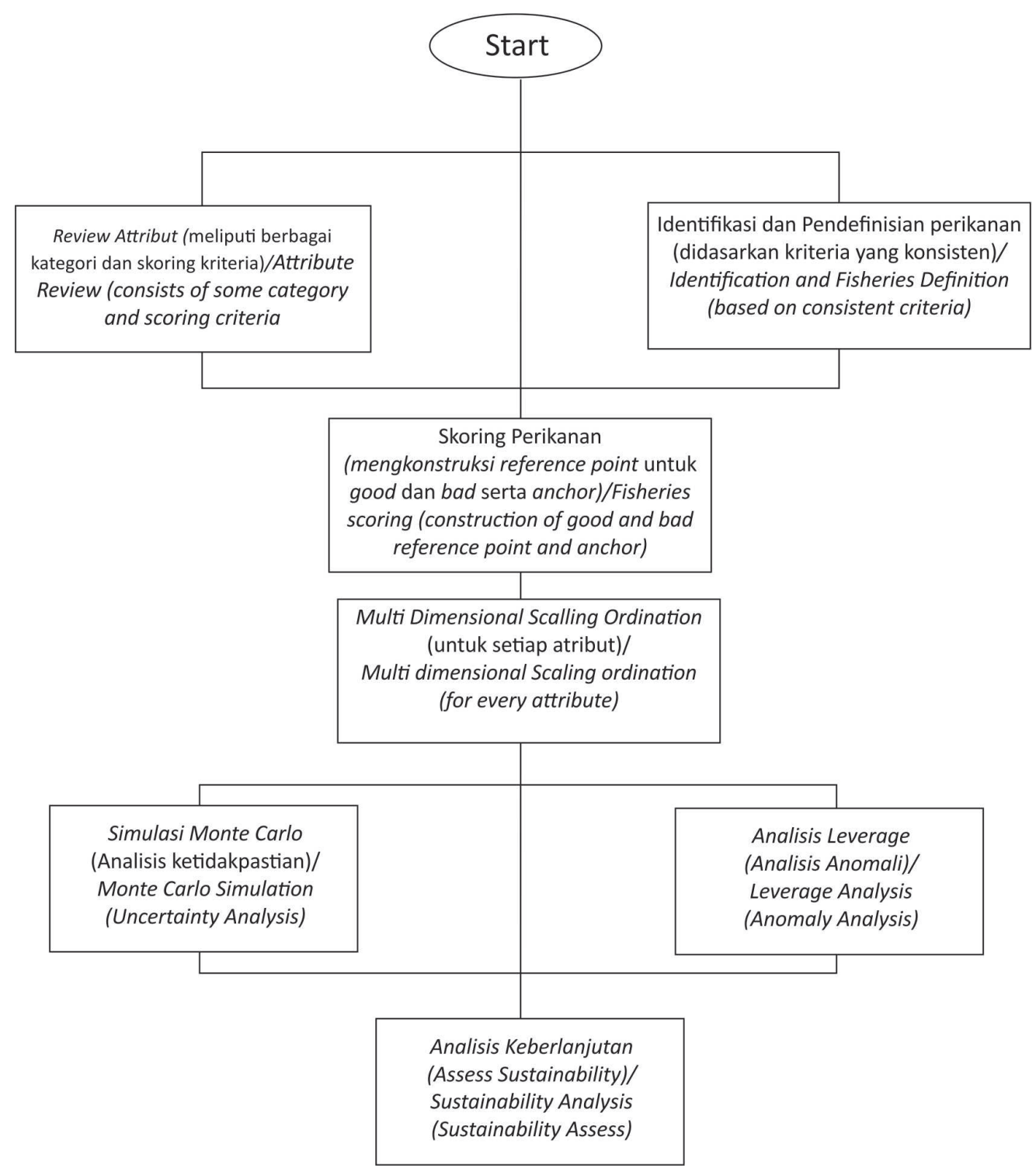

Gambar 1. Prosedur Analisis Raps-Tomini

Picture 1. Procedure of Raps Tomini Analysis 
Dengan kata lain, dua objek atau titik yang sama dipetakan dalam satu titik yang saling berdekatan satu sama lain. Sebaliknya objek atau titik yang tidak sama digambarkan dengan titik yang berjauhan. Teknik ordinasi MDS didasarkan pada jarak Euclidian yang pada ruang berdimensi $\mathrm{n}$ dituliskan sebagai berikut :

$$
d=\sqrt{\left(\left|x_{1}-x_{2}\right|^{2}+\left|y_{1}-y_{2}\right|^{2}+\left|z_{1}-z_{2}\right|^{2}+\ldots\right)}
$$

Konfigurasi dari suatu objek atau titik dalam MDS kemudian diaproksimasi dengan meregresikan jarak Euclidian $\left(d_{i j}\right)$ dari titik $i$ ke $j$ dengan titik asal $\left(d_{i j}\right)$ sebagaimana persamaan berikut :

$d_{i j}=a+b d_{i j}+e$

Ada tiga cara yang dapat digunakan untuk meregresikan persamaan (2.11) yaitu : metode Least Square, metode Least Squared bergantian yang didasarkan pada akar dari jarak Euclidian (Squared Distance) atau disebut dengan metode ALSCAL dan metode yang didasarkan pada Maximum Likelihood. Dari ketiga metode tersebut metode ALSCAL yang paling sesuai untuk Raps-Tomini dan tersedia software statistikanya (misalnya : SPSS dan SAS) (Alder et al, 2000). Metode ALSCAL dapat mengoptimisasi jarak kuadrat (squared distance $=d_{i j k}$ ) terhadap data kuadrat titik asal $\left(O_{i j k}\right)$ yang dalam tiga dimensi dituliskan dalam formula yang disebut $S$-Stress sebagai berikut :

$$
S=\sqrt{\frac{1}{m} \sum_{k=1}^{m}\left[\frac{\left.\sum_{i} \sum_{j}\left(d_{i j k}^{2}-o_{i j k}^{2}\right)^{2}\right]}{\sum_{i} \sum_{j} o_{i j k}^{4}}\right]},
$$

Dimana jarak kuadrat merupakan jarak Euclidian yang dibobot, dituliskan :

$$
d_{i j k}^{2}=\sum_{a=1}^{r} w_{k a}\left(x_{i a}-x_{j a}\right)^{2}
$$

Pada setiap pengukuran yang bersifat metrik, kondisi fit (goodness of fit), jarak titik pendugaan dengan titik asal menjadi sangat penting. Goodness of fit dalam MDS tidak lain adalah mengukur seberapa tepat konfigurasi dari suatu titik dapat mencerminkan data aslinya. Goodness of fit dalam MDS dicerminkan dari besaran nilai S-Stress. Dalam Raps-Tomini, model yang baik ditunjukkan dengan nilai $S$-Stress yang lebih kecil dari $0,25(S<0,25)$.

\section{Kajian Aspek Hukum Pemanfaatan Sumberdaya Perikanan Pelagis}

Kajian aspek hukum dalam pemanfaatan sumberdaya perikanan pelagis di perairan Teluk Tomini pada penelitian ini akan dijelaskan secara deskriptif berdasarkan hasil analisis tingkat pemanfaatan dan keberlanjutan yang didasari atas aspek legal yang berlaku yaitu : Undang-Undang, Peraturan Pemerintah, Keputusan Presiden, Peraturan Menteri, Keputusan Menteri, Peraturan Daerah dan aspek legal lainnya yang berkaitan dengan pengelolaan sumberdaya perikanan pelagis di perairan Teluk Tomini.

\section{Penyusunan Konsep Keterpaduan Pengelolaan dan Pengembangan Sumberdaya Perikanan}

Penyusunan konsep keterpaduan pengelolaan dan pengembangan sumberdaya perikanan pelagis di perairan Teluk Tomini pada penelitian ini akan dijelaskan secara deskriptif berdasarkan hasil pengkajian stok, analisis status keberlanjutan dan hasil kajian aspek hukum dalam pemanfaatan sumberdaya perikanan pelagis.

\section{ESTIMASI POTENSI LESTARI (MAXIMUM SUSTAINABLE YIELD (MSY)) DAN UPAYA OPTIMAL}

Produksi dan upaya penangkapan ikan pelagis di perairan Teluk Tomini secara akumulasi pada tahun 2002- 2011 diperlihatkan pada Tabel 1. 
Tabel 1. Produksi dan Upaya Penangkapan Ikan Pelagis di Perairan Teluk Pada Tahun 2002 2011.

Tabel 1. Production and Effort to Capture Pelagic Fish in the Gulf From The Year 2002 to 2011.

\begin{tabular}{|c|c|c|c|c|c|c|c|c|c|c|}
\hline \multirow{2}{*}{$\begin{array}{c}\text { Tahun/ } \\
\text { Year }\end{array}$} & \multicolumn{2}{|c|}{$\begin{array}{l}\text { Pukat Kantong/ } \\
\text { Seine Net }\end{array}$} & \multicolumn{2}{|c|}{$\begin{array}{l}\text { Pukat Cincin/ } \\
\text { Seine Net }\end{array}$} & \multicolumn{2}{|c|}{ Jaring Insang/Gill Net } & \multicolumn{2}{|c|}{ Jaring Angkat/Lift Net } & \multicolumn{2}{|c|}{ Pancing/Hook and line } \\
\hline & $\begin{array}{l}\text { Produksi/ } \\
\text { Production } \\
\text { (ton) }\end{array}$ & $\begin{array}{c}\text { Upaya/ } \\
\text { Effort } \\
\text { (trip) }\end{array}$ & $\begin{array}{l}\text { Produksi/ } \\
\text { Production } \\
\text { (ton) }\end{array}$ & $\begin{array}{c}\text { Upaya/ } \\
\text { Effort } \\
\text { (trip) }\end{array}$ & $\begin{array}{l}\text { Produksi/ } \\
\text { Production } \\
\text { (ton) }\end{array}$ & $\begin{array}{c}\text { Upaya/ } \\
\text { Effort } \\
\text { (trip) }\end{array}$ & $\begin{array}{l}\text { Produksi/ } \\
\text { Production } \\
\text { (ton) }\end{array}$ & $\begin{array}{c}\text { Upaya/ } \\
\text { Effort } \\
\text { (trip) }\end{array}$ & $\begin{array}{l}\text { Produksi/ } \\
\text { Produc- } \\
\text { tion } \\
\text { (ton) }\end{array}$ & $\begin{array}{c}\text { Upaya/ } \\
\text { Effort } \\
\text { (trip) }\end{array}$ \\
\hline 2002 & $5,290.3$ & 86,957 & $21,628.59$ & 32,115 & $3,903.44$ & 232,823 & $6,263.66$ & 43,113 & $14,925.48$ & $1,768,671$ \\
\hline 2003 & $5,444.24$ & 89,541 & $20,148.69$ & 31,387 & $3,390.41$ & 217,221 & $5,986.68$ & 41,413 & $23,576.63$ & $1,858,979$ \\
\hline 2004 & $6,041.68$ & 95,001 & $18,007.5$ & 28,813 & $5,605.76$ & 299,655 & $7,470.06$ & 49,042 & $25,353.24$ & $2,190,119$ \\
\hline 2005 & $3,363.37$ & 54,989 & $15,697.37$ & 23,537 & $6,884.45$ & 253,135 & $8,753.21$ & 60,639 & $21,616.47$ & $1,773,644$ \\
\hline 2006 & $4,648.28$ & 98,240 & $19,895.14$ & 32,216 & $8,165.41$ & 297,247 & $11,629.7$ & 55,245 & $31,727.07$ & $3,212,193$ \\
\hline 2007 & $6,811.97$ & 157,826 & $18,406.8$ & 32,752 & $6,190.19$ & 245,772 & $11,567.16$ & 64,848 & $33,911.39$ & $3,713,685$ \\
\hline 2008 & $4,953.16$ & 119,743 & $13,087.4$ & 19,327 & $7,704.68$ & 281,327 & $12,435.07$ & 62,709 & $38,302.52$ & $4,056,197$ \\
\hline 2009 & $4,745.83$ & 73,895 & $14,718.71$ & 25,989 & $12,676.78$ & 399,987 & $7,624.38$ & 60,586 & $44,973.61$ & 4,595,194 \\
\hline 2010 & $4,967.01$ & 141,306 & $18,202.04$ & 23,321 & $13,406.9$ & 328,479 & $6,742.58$ & 86,637 & $40,618.77$ & $4,605,321$ \\
\hline 2011 & $4,503.77$ & 172,354 & $16,859.11$ & 19,279 & $14,205.13$ & 350,928 & $5,808.92$ & 110,526 & $38,499.74$ & $6,344,775$ \\
\hline
\end{tabular}

Sumber : Statistik Perikanan Tangkap, Dinas Perikanan dan Kelautan Provinsi Gorontalo dan Provinsi Sulawesi Tengah (2002-2011) Source: Capture Fisheries Statistics, Fisheries and Marine Agency of Gorontalo and Central Sulawesi Pronvince (2002-2011)

Tabel 1 menunjukkan bahwa seluruh alat tangkap yakni : pukat kantong (seine net), pukat cincin (purse sein), jaring insang (gill net), jaring angkat (lift net) dan pancing (hook and line) berproduksi mulai dari tahun 2002 sampai dengan tahun 2011.

Estimasi MSY dilakukan dengan menggunakan model Schaefer dan Fox. Sebelum mengestimasi MSY terlebih dahulu dilakukan standarisasi alat tangkap, dan yang menjadi dasar standarisasi alat tangkap adalah pukat cincin (purse sein) karena memiliki rata-rata CPUE yang tertinggi dibandingkan dengan alat tangkap lainnya, hasil perhitungannya diperlihatkan pada Tabel 2.

Estimasi MSY dan upaya penangkapan optimal dengan mempergunakan formulasi Schaefer (1954), yakni CPUE $=a-b E$, dihasilkan persamaan :

CPUE $=0,904529-2,197 \mathrm{e}-006 \mathrm{E}$ dengan $R^{2}=0,291$.
MSY $=-a^{2} / 4 b=93.071,21$ ton/tahun

$\mathrm{E}_{\text {opt }}=-\mathrm{a} / 2 \mathrm{~b}=205.682$ trip $/$ tahun $=714$ alat/kapal standar (pukat cincin/purse sein).

Estimasi MSY dan upaya penangkapan optimal dengan menggunakan formulasi Fox (1970) yakni : $\operatorname{LnCPUE}=\mathrm{a}-\mathrm{bE}_{\mathrm{t}}$ dihasilkan persamaan :

Ln CPUE = -0,050577-3,357e-006 E dengan $R^{2}=0,336$.

MSY $=-1 / \mathrm{b}^{(\mathrm{a}-1)}=104.044,04$ ton/tahun $\mathrm{E}_{\text {opt }}=-1 / \mathrm{b}=297.619$ trip/tahun = 1033 alat/kapal standar (pukat cincin/ purse sein).

\section{KEBERLANJUTAN SUMBERDAYA PERIKANAN PELAGIS}

Analisis keberlanjutan sumberdaya perikanan pelagis di perairan Teluk Tomini didasarkan pada alat tangkap yang dipergunakan untuk menangkap ikan-ikan pelagis yakni : pukat kantong (seine net), pukat cincin (purse sein), jaring insang 
Tabel 2. Standarisasi Alat Tangkap Ikan Pelagis di Perairan Teluk Tomini Pada Tahun $2002-2011$.

Tabel 2. Standarization of Pelagic Fish Capture Devices in Tomini Gulf in the year 2002-2011.

\begin{tabular}{|c|c|c|c|c|c|c|c|c|}
\hline \multirow[b]{2}{*}{$\begin{array}{l}\text { Tahun } \\
\text { /Year }\end{array}$} & \multirow[b]{2}{*}{$\begin{array}{l}\text { Total Pen- } \\
\text { angkapan/ } \\
\text { Total Catch } \\
\text { (ton) }\end{array}$} & \multicolumn{5}{|c|}{ Upaya Penangkapan Standar (trip)/ Standard Catch Effort } & \multirow{2}{*}{$\begin{array}{c}\text { Total Upaya } \\
\text { Penangkapan } \\
\text { Standar } \\
\text { (trip)/ Total } \\
\text { Standard Catch } \\
\text { Effort }\end{array}$} & \multirow[b]{2}{*}{ CPUE } \\
\hline & & $\begin{array}{c}\text { Pukat } \\
\text { Kantong/ } \\
\text { Seine Net }\end{array}$ & $\begin{array}{l}\text { Pukat } \\
\text { Cincin/ } \\
\text { Purse } \\
\text { sein }\end{array}$ & $\begin{array}{l}\text { Jaring } \\
\text { Insang/ } \\
\text { Gill Net }\end{array}$ & $\begin{array}{c}\text { Jaring } \\
\text { Angkat/ } \\
\text { Lift Net }\end{array}$ & $\begin{array}{l}\text { Pancing/ } \\
\text { Hook an } \\
\text { Line }\end{array}$ & & \\
\hline 2002 & $52,011.47$ & 7,855 & 32,115 & 5,796 & 9,301 & 22,162 & 77,229 & 0.673471 \\
\hline 2003 & $58,546.65$ & 8,481 & 31,387 & 5,281 & 9,326 & 36,727 & 91,202 & 0.641945 \\
\hline 2004 & $62,478.24$ & 9,667 & 28,813 & 8,970 & 11,953 & 40,567 & 99,970 & 0.62497 \\
\hline 2005 & $56,314.87$ & 5,043 & & 10323 & 13,125 & 32,412 & 84,440 & 0.666922 \\
\hline 2006 & $76,065.60$ & 7,527 & 32,216 & $13,, 222$ & 18,832 & 51,375 & 123,172 & 0.617556 \\
\hline 2007 & $76,887.51$ & 1,2121 & 32,752 & 11,014 & 20,582 & 60,340 & 136,809 & 0.562006 \\
\hline 2008 & $76,482.83$ & 7,315 & 19,327 & 11,378 & 18,364 & 56,564 & 112,948 & 0.677151 \\
\hline 2009 & $84,739.31$ & 8,380 & 25,989 & 22,384 & 13,462 & 79,410 & 149,625 & 0.566345 \\
\hline 2010 & $83,937.30$ & 6,364 & 23,321 & 17,177 & 8,639 & 52,042 & 107,543 & 0.7805 \\
\hline 2011 & $79,876.67$ & 5,150 & 19,279 & 16,244 & 6,643 & 44,026 & 91,342 & 0.874479 \\
\hline
\end{tabular}

Sumber : Data Diolah (2012)/Source: Data Processed (2012)

(gill net), jaring angkat (lift net) dan pancing (hook and line).

Dalam analisis keberlanjutan ini digunakan teknik Raps-Tomini (modifikasi dari Rapfish) yakni analisis dengan metode Multi Dimensional Scalling (MDS) dengan lima dimensi yaitu : ekonlogi, ekonomi, sosial, teknologi dan etika, hukum dan regulasi.

\section{Dimensi Ekologi}

Dimensi ekologi terdiri dari 10 (sepuluh) atribut yaitu : (1) tingkat eksploitasi SDI pelagis; (2) keragaman rekruitmen; (3) perubahan tingkat tropik; (4) jangkauan migrasi; (5) penurunan hasil tangkapan; (6) ukuran ikan yang tertangkap; (7) ikan yang tertangkap sebelum dewasa; (8) tangkapan non target; (9) jumlah species ikan yang tertangkap; (10) produktivitas primer.

Nilai leverage masing-masing atribut adalah sebagai berikut : (1) tingkat eksploitasi SDI pelagis = 1,04 (2) keragaman rekruitmen $=1,98$ (3) perubahan tingkat tropik $=2,20$ (4) jangkauan migrasi $=2,41$
(5) penurunan hasil tangkapan $=4,12$ (6) ukuran ikan yang tertangkap $=2,32$ (7) ikan yang tertangkap sebelum dewasa $=2,16$ (8) tangkapan non target $=1,75$ (9) jumlah species ikan yang tertangkap $=1,33 \quad(10)$ produktivitas primer $=3,02$

\section{Dimensi Ekonomi}

Dimensi ekonomi terdiri dari 10 (sepuluh) atribut yaitu : (1) keuntungan usaha perikanan; (2) kontribusi PDRB sektor perikanan; (3) penghasilan relatif terhadap UMR; (4) penerapan bagi hasil; (5) kerjasama usaha perikanan; (6) pendapatan lain; (7) tenaga kerja sektor perikanan; (8) manfaaat kegiatan perikanan; (9) pasar dan (10) Subsidi.

Nilai leverage masing-masing atribut adalah sebagai berikut : (1) keuntungan usaha perikanan $=2,21$ (2) kontribusi PDRB sektor perikanan $=3,53$ (3) penghasilan relatif terhadap UMR = 3,06 (4) penerapan bagi hasil $=1,82$ (5) kerjasama usaha perikanan $=3,86$ (6) pendapatan lain $=6,07$ (7) tenaga kerja sektor perikanan $=3,82$ (8) manfaaat 
kegiatan perikanan $=3,99$ (9) Pasar $=3,68$ (10) Subsidi $=2,85$.

\section{Dimensi Sosial}

Dimensi sosial terdiri dari 9 (sembilan) atribut yaitu : (1) hubungan sosial; (2) pertumbuhan nelayan pendatang; (3) jumlah rumah tangga nelayan (4) pengetahuan tentang lingkungan; (5) tingkat pendidikan; (6) konflik antar nelayan; (7) Tingkat partisipasi nelayan; (8) Porsi pendapatan keluarga; (9) Keterlibatan anggota keluarga.

Nilai leverage masing-masing atribut adalah sebagai berikut : (1) hubungan sosial $=1,49$ (2) pertumbuhan nelayan pendatang $=3,48$ (3) jumlah rumah tangga nelayan $=5,35$ (4) pengetahuan tentang lingkungan $=6,65$ (5) tingkat pendidikan $=8,14$ (6) konflik antar nelayan $=5,63$ (7) tingkatpartisipasi nelayan $=5,65$ (8) porsi pendapatan keluarga $=3,86$ (9) keterlibatan anggota keluarga $=1,68$.

\section{Dimensi Teknologi}

Dimensi teknologi terdiri dari 10 (sepuluh) atribut yaitu : (1) lama trip penangkapan; (2) tempat pendaratan hasil tangkapan; (3) pengolahan sebelum penjualan ; (4) penanganan di atas kapal; (5) sifat alat tangkap; (6) selektivitas alat tangkap; (7) alat bantu penangkapan; (8) ukuran kapal ikan; (9) mesin kapal dan (10) pengaruh negatif alat tangkap.

Nilai leverage masing-masing atribut adalah sebagai berikut : (1) lama trip penangkapan $=0,90$ (2) tempat pendaratan hasil tangkapan $=1,92$ (3) pengolahan sebelum penjualan $=5,64$ (4) penanganan di atas kapal $=4,36(5)$ sifat alat tangkap $=5,46(6)$ selektivitas alat tangkap $=5,63$ (7) alat bantu penangkapan $=4,49$ (8) ukuran kapal ikan $=2,22$ (9) mesin kapal = 3,04 (10) pengaruh negatif alat tangkap $=1,78$.

\section{Dimensi Etika, Hukum dan Regulasi}

Dimensi etika, hukum dan regulasi terdiri dari 9 (sembilan) atribut yaitu (1) penegakkan hukum; (2) ketersediaan pekerjaaan lain; (3) ketersediaan aturan formal pengelolaan; (4) keterlibatan dalam pengambilan keputusan; (5) tradisi/kepercayaan; (6) pembatasan akses penangkapan; (7) pengelolaan ekosistem; (8) intensitas pelanggaran hukum; (9) buangan hasil tangkapan sampingan.

Nilai leverage masing-masing atribut adalah sebagai berikut : (1) penegakkan hukum $=2,32$ (2) ketersediaan pekerjaaan lain $=1,95$ (3) ketersediaan aturan formal pengelolaan $=2,05$ (4) keterlibatan dalam pengambilan keputusan $=2,52(5)$ tradisi/ kepercayaan $=1,49$ (6) pembatasan akses penangkapan $=3,66$ (7) pengelolaan ekosistem $=1,91$ (8) intensitas pelanggaran hukum $=2,99$ (9) buangan hasil tangkapan sampingan $=1,45$.

Secara ringkas matriks tingkat keberlanjutan sumberdaya perikanan di perairan Teluk Tomini berdasarkan dimensi dan alat tangkap disajikan pada Tabel 3.

\section{ASPEK HUKUM KEBIJAKAN PENGELOLAAN SUMBERDAYA PERIKANAN PELAGIS}

Pengelolaan sumberdaya perikanan pelagis di perairan Teluk Tomini didasari atas pendekatan kawasan ekologi sebagai suatu kesatuan perairan yang didalamnya terkandung sumberdaya ikan yang bersifat common property, sehingga pengelolaannya perlu diatur sedemikian rupa agar sumberdaya tersebut terjamin keberlanjutannya. Pasal 1 ayat 7 UU No.45 Tahun 2009 tentang perikanan menyatakan bahwa pengelolaan perikanan adalah semua upaya, termasuk proses yang terintegrasi dalam pengumpulan informasi, analisis, perencanaan, konsultasi, pembuatan keputusan, alokasi sumber daya ikan, dan implementasi serta penegakan hukum dari peraturan perundang-undangan di bidang perikanan, yang dilakukan oleh pemerintah atau otoritas lain yang diarahkan untuk mencapai kelangsungan produktivitas sumber daya hayati perairan dan tujuan yang telah disepakati. Selanjutnya dalam Pasal 2 dinyatakan bahwa : Pengelolaan perikanan 
Tabel 3. Matriks Tingkat Keberlanjutan Sumberdaya Perikanan Pelagis di Perairan Teluk Tomini. Table 3. Matrixs of Resources Sustanibility Level for Pelagic Fish in Tomini Gulf.

\begin{tabular}{|c|c|c|c|c|c|c|}
\hline No & $\begin{array}{l}\text { Alat Tangkap/Fishing Gear } \\
\text { Dimensi/Dimension }\end{array}$ & $\begin{array}{c}\text { Pukat } \\
\text { Kantong/ } \\
\text { Seine Net } \\
\end{array}$ & $\begin{array}{c}\text { Pukat } \\
\text { Cincin/ } \\
\text { Purse Sein } \\
\end{array}$ & $\begin{array}{l}\text { Jaring } \\
\text { Insang/ } \\
\text { Gill Net }\end{array}$ & $\begin{array}{l}\text { Jaring } \\
\text { Angkat/ } \\
\text { Lift Net }\end{array}$ & $\begin{array}{l}\text { Pancing/ } \\
\text { Hook } \\
\text { and Line }\end{array}$ \\
\hline \multirow[t]{5}{*}{1} & $\begin{array}{l}\text { Ekologi (10 Atribut)/ } \\
\text { Ecology (10 Atributte) }\end{array}$ & & & & & \\
\hline & $\begin{array}{l}\text { Korelasi kuadrat }\left(\mathrm{R}^{2}\right) / \\
\text { Quadrate correlation }\left(R^{2}\right)(\%)\end{array}$ & 95.71 & 95.71 & 95.71 & 95.71 & 95.71 \\
\hline & Nilai stress/Stress value (\%) & 14.98 & 14.98 & 14.98 & 14.98 & 14.98 \\
\hline & Nilai ordinasi/ Ordination value & 86.50 & 86.60 & 81.03 & 65.33 & 95.39 \\
\hline & $\begin{array}{l}\text { Tingkat keberlanjutan/ } \\
\text { Sustainability level }\end{array}$ & $\begin{array}{l}\text { Baik/ } \\
\text { Good }\end{array}$ & $\begin{array}{l}\text { Baik/ } \\
\text { Good }\end{array}$ & $\begin{array}{l}\text { Baik/ } \\
\text { Good }\end{array}$ & $\begin{array}{l}\text { Cukup/ } \\
\text { Good }\end{array}$ & $\begin{array}{l}\text { Baik/ } \\
\text { Good }\end{array}$ \\
\hline \multirow[t]{5}{*}{2} & $\begin{array}{l}\text { Ekonomi (10 Atribut)/ } \\
\text { Economy (10 Atributte) }\end{array}$ & & & & & \\
\hline & $\begin{array}{l}\text { Korelasi Kuadrat }\left(\mathrm{R}^{2}\right) / \\
\text { Quadrate correlation }\left(R^{2}\right)(\%)\end{array}$ & 94.99 & 94.99 & 94.99 & 94.99 & 94.99 \\
\hline & Nilai Stress/Stress value (\%) & 14.10 & 14.10 & 14.10 & 14.10 & 14.10 \\
\hline & Nilai Ordinasi/ Ordination value & 58.96 & 68.96 & 53.67 & 53.07 & 62.85 \\
\hline & $\begin{array}{l}\text { Tingkat keberlanjutan/ } \\
\text { Sustainability level }\end{array}$ & $\begin{array}{l}\text { Cukup/ } \\
\text { Fair }\end{array}$ & $\begin{array}{l}\text { Cukup/ } \\
\text { Fair }\end{array}$ & $\begin{array}{l}\text { Cukup/ } \\
\text { Fair }\end{array}$ & $\begin{array}{l}\text { Cukup/ } \\
\text { Fair }\end{array}$ & $\begin{array}{l}\text { Cukup/ } \\
\text { Fair }\end{array}$ \\
\hline \multirow[t]{5}{*}{3} & $\begin{array}{l}\text { Sosial (9 Atribut)/ } \\
\text { Social (9 Atributte) }\end{array}$ & & & & & \\
\hline & $\begin{array}{l}\text { Korelasi kuadrat }\left(\mathrm{R}^{2}\right) / \\
\text { Quadrate correlation }\left(R^{2}\right)(\%)\end{array}$ & 89.84 & 89.84 & 89.84 & 89.84 & 89.84 \\
\hline & Nilai stress/Stress value (\%) & 15.88 & 15.88 & 15.88 & 15.88 & 15.88 \\
\hline & Nilai ordinasi/ Ordination value & 63.96 & 65.75 & 63.13 & 57.32 & 56.45 \\
\hline & $\begin{array}{l}\text { Tingkat Keberlanjutan/ } \\
\text { Sustainability level }\end{array}$ & $\begin{array}{l}\text { Cukup/ } \\
\text { Fair }\end{array}$ & $\begin{array}{l}\text { Cukup/ } \\
\text { Fair }\end{array}$ & $\begin{array}{l}\text { Cukup/ } \\
\text { Fair }\end{array}$ & $\begin{array}{l}\text { Cukup/ } \\
\text { Fair }\end{array}$ & $\begin{array}{l}\text { Cukup/ } \\
\text { Fair }\end{array}$ \\
\hline \multirow[t]{5}{*}{4} & $\begin{array}{l}\text { Teknologi (10 Atribut)/ } \\
\text { Technology (10Atributte) }\end{array}$ & & & & & \\
\hline & $\begin{array}{l}\text { Korelasi kuadrat }\left(R^{2}\right) / \\
\text { Quadrate correlation }\left(R^{2}\right)(\%)\end{array}$ & 93.12 & 93.12 & 93.12 & 93.12 & 93.12 \\
\hline & Nilai Stress/Stress value (\%) & 13.46 & 13.46 & 13.46 & 13.46 & 13.46 \\
\hline & Nilai Ordinasi/ Ordination Value & 45.19 & 42.80 & 77.60 & 43.77 & 81.91 \\
\hline & $\begin{array}{l}\text { Tingkat keberlanjutan/ } \\
\text { Sustainability level }\end{array}$ & $\begin{array}{l}\text { Kurang/ } \\
\text { Less }\end{array}$ & $\begin{array}{l}\text { Kurang / } \\
\text { Less }\end{array}$ & $\begin{array}{l}\text { Baik/ } \\
\text { Good }\end{array}$ & $\begin{array}{c}\text { Kurang } \\
\text { Less }\end{array}$ & $\begin{array}{l}\text { Baik/ } \\
\text { Good }\end{array}$ \\
\hline \multirow[t]{5}{*}{5} & $\begin{array}{l}\text { Etika, Hukum dan Regulasi } \\
\text { (9 Atribut)/ Ethisc, Law and } \\
\text { Regulation (9 Atributte) }\end{array}$ & & & & & \\
\hline & $\begin{array}{l}\text { Korelasi kuadrat }\left(\mathrm{R}^{2}\right) / \\
\text { Quadrate correlation }\left(R^{2}\right)(\%)\end{array}$ & 94.55 & 94.55 & 94.55 & 94.55 & 94.55 \\
\hline & Nilai stress/Stress value (\%) & 16.62 & 16.62 & 16.62 & 16.62 & 16.62 \\
\hline & Nilai ordinasi/ Ordination value & 39.65 & 39.65 & 36.52 & 30.29 & 36.51 \\
\hline & $\begin{array}{l}\text { Tingkat keberlanjutan/ } \\
\text { Sustainability Level }\end{array}$ & $\begin{array}{c}\text { Kurang/ } \\
\text { Less }\end{array}$ & $\begin{array}{c}\text { Kurang/ } \\
\text { Less }\end{array}$ & $\begin{array}{c}\text { Kurang/ } \\
\text { Less }\end{array}$ & $\begin{array}{l}\text { Kurang/ } \\
\text { Less }\end{array}$ & $\begin{array}{c}\text { Kurang/ } \\
\text { Less }\end{array}$ \\
\hline
\end{tabular}


dilakukan berdasarkan asas manfaat, keadilan, kebersamaan, kemitraan, kemandirian, pemerataan, keterpaduan, keterbukaan, efisiensi, kelestarian dan pembangunan yang berkelanjutan.

Peraturan Menteri Dalam Negeri Nomor 30 Tahun 2010 tentang Pedoman Pengelolaan Sumberdaya di Wilayah Laut Pasal 1 ayat 3 menjelaskan bahwa wilayah laut adalah ruang laut yang merupakan kesatuan geografis beserta segenap unsur terkait yang batas dan sistemnya ditentukan berdasarkan aspek administratif dan/atau aspek fungsional yang diukur dari garis pantai ke arah laut lepas dan/atau ke arah perairan kepulauan untuk provinsi paling jauh 12 (duabelas) mil laut dan $1 / 3$ (sepertiga) dari wilayah kewenangan provinsi untuk kabupaten/kota termasuk wilayah pesisir dan pulau-pulau kecil. Sumberdaya laut adalah unsur hayati, non hayati yang terdapat di wilayah laut dan dapat digunakan untuk meningkatkan kesejahteraan manusia (Pasal 1 ayat 2). Selanjutnya dalam Pasal 2 ayat 2 dijelaskan bahwa kewenangan untuk mengelola sumberdaya di wilayah laut paling jauh 12 (dua belas) mil laut diukur dari garis pantai ke arah laut lepas dan/atau ke arah perairan kepulauan untuk provinsi dan $1 / 3$ (sepertiga) dari wilayah kewenangan provinsi untuk kabupaten/kota. Sebagai suatu kawasan yang terdiri dari beberapa kabupaten/kota dan provinsi, perairan Teluk Tomini yang memiliki sumberdaya perikanan pelagis harus dikelola berdasarkan peraturan yang ada dengan menjalin kerjasama antar pemerintah baik pusat, provinsi maupun kabupaten. Untuk mengefektifkan kerjasama ini perlu dibentuk institusi yang akan menjalankan rencana pengelolaan sumberdaya perikanan, dimana institusi tersebut harus berada pada payung hukum yang jelas agar kewenangan pengelolaan masing-masing Kepala Daerah dapat disinergikan sehingga pemanfaatan sumberdaya perikanan pelagis dapat dimaksimalkan dengan tetap memperhatikan keberlanjutannya.

\section{KONSEP KAWASAN TERPADU PENGELOLAAN SUMBERDAYA PERIKANAN PELAGIS}

Selama ini kebijakan pengelolaan sumberdaya perikanan pelagis di perairan Teluk Tomini dilakukan secara parsial, masing-masing kabupaten/kota dan propinsi membuat kebijakan sendiri-sendiri. Adanya Undang-Undang Nomor 32 Tahun 2004 tentang Pemerintahan Daerah dan Permen Dalam Negeri Nomor 30 Tahun 2010 tentang Pedoman Pengelolaan Sumberdaya di Wilayah Laut menjadikan laut terkapling-kapling berdasarkan kewenangan yang diberikan oleh Undang-Undang sementara sumberdaya ikannya secara dinamis berpindah-pindah antara perairan kabupaten/kota. Sejak dahulu sebelum peraturan-peraturan ini lahir, nelayan perairan Teluk Tomini telah melakukan penangkapan ikan lintas perairan kabupaten/kota dan provinsi. Dengan adanya peraturan ini maka pemanfaatan sumberdaya ikan oleh nelayan menjadi terkendala. Mereka yang melakukan penangkapan ikan lintas perairan kabupaten/ kota harus mengurus izin sebagai nelayan andon yang tidak jarang menimbulkan pungutan liar dalam prakteknya di lapangan. Keadaan ini juga seringkali menimbulkan konflik antara nelayan setempat dengan nelayan andon.

Berdasarkan hasil kajian potensi, status keberlanjutan dan kajian hukum serta mencermati fenomena yang terjadi di lapangan sebagaimana telah dijelaskan, maka dibuat konsep pembentukan kawasan terpadu pengelolaan sumberdaya perikanan Teluk Tomini. Keterpaduan yang dimaksudkan adalah keterpaduan dalam kewenangan dan kebijakan pengelolaan sumberdaya perikanan yang dibuat oleh masing-masing pemerintah kabupaten/ kota, provinsi dan pusat. Konsep ini bertujuan untuk menghilangkan sekat-sekat kewenangan pada masing-masing perairan kabupaten/ kota dalam pemanfaatan sumberdaya perikanan di perairan Teluk Tomini. Pembentukan kawasan terpadu pengelolaan sumberdaya perikanan Teluk Tomini akan berjalan dengan baik jika disertai dengan penciptaan payung hukum, pembuatan kelembagaan, penyusunan 
rencana pemanfaatan sumberdaya perikanan, pembentukan sistem pendataan dan informasi dan pembentukan sistem pengawasan dan monitoring. Kelima unsur tersebut harus dilakukan secara simultan agar tujuan kebijakan pengelolaan sumberdaya perikanan secara terpadu dan berkelanjutan dapat tercapai.

\section{PENUTUP}

Potensi lestari sumberdaya perikanan pelagis di perairan Teluk Tomini dengan menggunakan model Schaefer sebesar 93.071,21 ton/tahun dan dengan menggunakan model Fox sebesar 104.044,04 ton/tahun. Dengan tingkat pemanfaatan under fishing. Dimensi etika, hukum dan regulasi kurang mendukung keberlanjutan sumberdaya perikanan pelagis di perairan Teluk Tomini. Terutama pada atribut pembatasan akses penangkapan dan intensitas pelanggaran hukum. Pengelolaan sumberdaya perikanan pelagis di perairan Teluk Tomini secara terpadu dan berkelanjutan belum didasari oleh peraturan yang memadai. Strategi kebijakan pengelolaan sumberdaya perikanan pelagis secara berkelanjutan adalah dengan pembentukan kawasan otonomi pengelolaan terpadu dengan payung hukum yang mengakomodasi kewenangan pengelolaan pemerintah pusat, provinsi dan kabupaten/ kota.

Meskipun tingkat pemanfataannya masih under fishing, namun pada tahuntahun terakhir sudah mendekati MSY maka upaya penangkapan selayaknya dipertahankan. Aspek etika, hukum dan regulasi terutama pada atribut pembatasan akses penangkapan dan intensitas pelanggaran hukum perlu mendapat perhatian pemerintah agar keberlanjutan sumberdaya perikanan pelagis di perairan Teluk Tomini dapat terjamin

\section{DAFTAR PUSTAKA}

Alder, J., T.J. Pitcher, D. Preikshot, K. Kaschner and B. Ferriss. 2000. How Good is Good?A Rapid Appraisal Technique for Evaluation of The Sustainability Status Fisheries of North Atlantic. In Pauly and
Pitcher (eds.) Methods for Evaluation The Impacts of Fisheries on The North Atlantic Ecosystem. Fisheries Center Research Report. 8 (2).

Anonim. 2002 - 2011. Statistik Perikanan Tangkap Provinsi Gorontalo. Dinas Perikanan dan Kelautan Provinsi Gorontalo. Gorontalo. . 2002 - 2011. . Statistik Perikanan Tangkap Provinsi Sulawesi Tengah. Dinas Perikanan dan Kelautan Provinsi Sulawesi Tengah. Palu

. 2003.Wilayah Pengelolaan Perikanan Laut Indonesia. Komisi Nasional Pengkajian Stok Ikan. Departemen Kelautan dan Perikanan. Jakarta.

. 2004. Undang-Undang Nomor 32 Tahun 2004 Tentang Pemerintah Daerah. Lembaran Negara RI No. 125. Sekretariat Negara. Jakarta.

. 2005. Teluk Tomini : Ekologi, Potensi Sumberdaya, Profil Perikanan dan Biologi Beberapa Jenis Ikan Ekonomis Penting. Departemen Kelautan dan Perikanan. Jakarta.

2007. Undang-Undang Nomor 327 Tahun 2007 Tentang Pengelolaan Wilayah Pesisir dan Pulau-Pulau Kecil. Lembaran Negara No. 84. Sekretariat Negara. Jakarta.

- 2009a. Kesepakatan Bersama Pengelolaan Teluk Tomini Secara Terpadu dan Berkelanjutan. Manado-Sulawesi Utara.

. 2009b. Rencana Strategis Pengelolaan Teluk Tomini Secara Terpadu dan Berkelanjutan. Kerjasama Pemerintah Provinsi Sulawesi Tengah, Sulawesi Utara dan Kementerian Lingkungan Hidup. Manado-Sulawesi Utara. . 2009c. Undang-Undang Nomor 45 Tahun 2009 Tentang Perikanan. Lembaran Negara No. 154. Sekretariat Negara. Jakarta. . 2010. Peraturan Menteri Dalam Negeri Nomor. 30 Tahun 2010 Tentang Pedoman Pengelolaan Sumberdaya di Wilayah Laut. Kementerian Dalam Negeri. Jakarta.

Anonim. 2011. Laporan Akhir Penyusunan Zonasi Rinci Kawasan Teluk Tomini. Direktorat 
Jenderal Kelautan, Pesisir dan PulauPulau Kecil. Kementerian Kelautan dan Perikanan. Jakarta.

Charles, A.T. 2001. Suistainable Fisheries System. In Pitcher T.J. (Series Eds.). Fish and Aquatic Resources Series. Blackwell Science. Oxford.

Clarke, R.P., S.S. Yoshimoto and S.G. Pooley. 1992. A Bioeconomic Analysis of the Northwestern Hawaiian Islands Lobster Fishery. Marine Resource Economics. Vol. 7. 115-140pp. Printed in USA.

Dahuri, R., J. Rais, S.P. Ginting dan M.J. Sitepu. 2001. Pengelolaan Sumberdaya Wilayah Pesisir da Lautan Secara Terpadu. PT. Pradnya Paramita. Jakarta.

Fauzi, A. dan S. Anna. 2005. Pendekatan Sumberdaya Perikanan dan Kelautan Untuk Analisis Kebijakan. PT. Gramedia Pustaka Utama. Jakarta.

Fox, W.W. 1970. An Experimental Surplus Yield Model for Optimazing Exploited Fish Population. Trans.Am.Fish.Soc. 99(1):8088pp.

King, M.1995. Fisheries Biology, Assesment and Management. Fishing News Book. Greath Britain. 266-267pp.

Koswara, B.2009. Pengelolaan Sumberdaya Perikanan di Daerah Padat Tangkap Melalui Pemberdayaan Nelayan Skala-Kecil Dalam Konteks Pembangunan Berkelanjutan. Orasi IImiah. Disampaikan pada Puncak Acara Dies Natalis ke-4 Fakultas Perikanan dan ilmu Kelautan UNPAD. Bandung.
Masyahoro, A. 2004. Model Pengembangan Perikanan Purse Seine yang Berkelanjutan di Perairan Kabupaten Parigi Moutong, Teluk Tomini. Disertasi. Sekolah Pasca Sarjana Institut Pertanian Bogor. 236 hal.

Nazir, M.2003. Metode Penelitian. PT. Ghalia Indonesia. Jakarta.

Nikijuluw, V.P. 2002. Rezim Pengelolaan Sumberdaya Perikanan. PT. Pustaka Cidesindo. Jakarta.

Olii, A.H. 2007. Analisis Kapasitas Perikanan Tangkap dalam Rangka Pengelolaan Armada Penangkapan di Provinsi Gorontalo. Disertasi. Sekolah Pasca Sarjana Institut Pertanian Bogor. 217 hal.

Panayotou, T. 1982. Management Concepts for Small-scale Fisheries : Economic and Social Aspect. FAO Fish Tech.Pap.,(228) : 53p.

Pitcher,T.J. 1999. Rapfish. A Rapid Appraisal Technique For Fisheries, And Its Application The Code of Conduct Responsible Fisheries. FAO. Rome.

Russel, E.S. 1931. Some Theoritical Considerations on the Overfishing Problem.J.Cons.,CIEM 6 (1): 3-20.

Schaefer, M. 1954. Same Consideration of Population Dynamics and Economics in Relation to the Management of the Commercial Marine Fisheries. Journal of Fisheries Research Board of Canada. 14 (5) : $669-681$.

Sudradjat.2006. Metode Penarikan Sampel dan Panyusunan Skala. Fakultas Pertanian Universitas Padjajaran Bandung. Bandung. 